DOI: https://doi.org/10.24867/03LR01Vranic

\title{
DŽENTRIFIKACIJA KAO FENOMEN DRUŠTVENO-EKONOMSKE I PROSTORNE TRANSFORMACIJE
}

\section{GENTRIFICATION AS THE PHENOMENON OF SOCIO-ECONOMIC AND SPATIAL TRANSFORMATION}

\author{
Anđela Vranić, Dejana Nedučin, Fakultet tehničkih nauka, Novi Sad
}

\section{Oblast - PLANIRANJE I UPRAVLJANJE REGIONALNIM RAZVOJEM}

Kratak sadržaj - Džentrifikacija (urbana džentrifikacija) je proces u kome se fizički degradirani stambeni fond ili čitavi kvartovi, najčešće naselja sa stanovništvom nižeg društveno-ekonomskog sloja, pretvaraju u zone sa stanovanjem za dobrostojeće pripadnike srednje klase, koji se doseljavaju umesto originalnog stanovništva koje sebi ne može da priušti povećanje dažbina $i$ troškova života. Predstavlja formiranje stambenih naselja namenjenih dobrovoljcima, ali delimično $i$ izmiče preciznom definisanju. Promovisana je kao način dopunjavanja identiteta izborom životnog stila, kritikovana kao instrument neoliberalne urbane politike namenjene klasnoj segregaciji. Rad analizira džentrifikaciju kao socio-ekonomskio fenomen $i$ kao fenomen urbanizma.

Ključne reči: džentrifikacija, klasna segregacija, društveno-prostorna diferencijacija

Abstract - Gentrification (urban gentrification) is a process in which the physically degraded housing stock or entire neighborhoods, the most frequent settlements with the population of the lower socio-economic layer, are converted into residential areas for prosperous middle class members who move in place of the original population that can not afford it because of increase of charges and cost of living. Gentrification is the formation of residential settlements intended for volunteers, but partly avoids precise definition. It is promoted as a way to supplement identity by choosing a lifestyle, criticized as an instrument of a neoliberal urban policy aimed at class segregation. gentrification is analyzed as a sociological phenomenon and as a phenomenon of urbanism.

Key words: gentrification, class segregation, sociospatial differentiation

\section{UVOD}

Postoji veliki nesklad u definicijama džentrifikacije koje se koriste u naučnim istraživanjima i teorijskim radovima. Ipak, sve definicije slažu se da je u pitanju proces formiranja naselja sa primarno rezidencijalnom funkcijom, sa stanovništvom homogenim po (srednjem ili visokom) simboličkom i društveno-ekonomskom statusu.

\section{NAPOMENA:}

Ovaj rad proistekao je iz master rada čiji mentor je bio dr Dejana Nedučin, docent.
Anglicizam džentrifikacija, koji nema adekvatni sinonim u srpskom jeziku, potiče od termina džentri (eng. gentry). Džentri je, kao indikator identiteta, klasne pripadnosti i prostornog kapitala, označavao osobu koja se isticala džentlmenskim vaspitanjem, pripadala aristokratiji, a aristokratski status stekla posedovanjem zamašnog zemljišnog poseda.

Vremenom se značenje pojma džentri proširilo tako da obuhvati sve aspirante na poziciju elite, ostajući neraskidivo vezano za kapital u nekretninama kojim nova elita dokazuje svoje (kvazi) plemstvo.

Džentrifikacija je u većini istraživanja barem implicitno tretirana kao pozitivna ili negativna. Kako konstatuju Vesselinov i Cazessus [1], zasad se nije razvio „kanonski” akademski pristup proučavanju džentrifikacije. Sikora [2] zaključuje da se perspektive posmatranja džentrifikacije polarizuju po osama orijentacije na proizvodnju/potrošnju, ekonomiju/kulturu, marksistička/postmodernistička objašnjenja.

Ne postoji kanonska metodologija za proučavanje džentrifikacije. Sikora ilustruje i razmimoilaženje u izboru kriterijuma za džentrifikaciju kod brojnih istraživača, konstatujući da se zbog toga ona ubraja u tzv. ,haotične koncepte" [3].

Upadljivo je da naselja koja nastanjuje srednja i viša klasa teže da postignu ekskluzivnost korišćenja, odnosno da nad ne-rezidentima sprovedu različite mere zabrane prolaska, od fizičkih barijera i sistema bezbednosti (engl. gated communities), do obeshrabrivanja prolaznika simboličkim sredstvima da se na njihovoj površini nađu. U oba slučaja povlači se granica, iako različite propustljivosti, između privatnog i javnog prostora, što ima velike društvene $\mathrm{i}$ prostorne implikacije. Zato se renovirana naselja sa izmenjenom strukturom vlasnika i novonastala ,zatvorena" naselja (eng. gated communities) mogu tretirati zajedno kao rezultat sličnih procesa društveno-prostorne stratifikacije, dok procesi formiranja CBD (eng. Central Business District) u istorijskim centrima gradova neće biti smatrani džentrifikacijom.

Džentrifikacija (tačnije urbana džentrifikacija) je proces $u$ kome se fizički degradirani stambeni fond ili čitavi kvartovi, najčešće naselja sa stanovništvom nižeg društvenoekonomskog sloja, pretvaraju u zone sa stanovanjem za dobrostojeće pripadnike srednje klase, koji se doseljavaju umesto originalnog stanovništva koje sebi ne može da priušti povećanje dažbina i troškova života. 


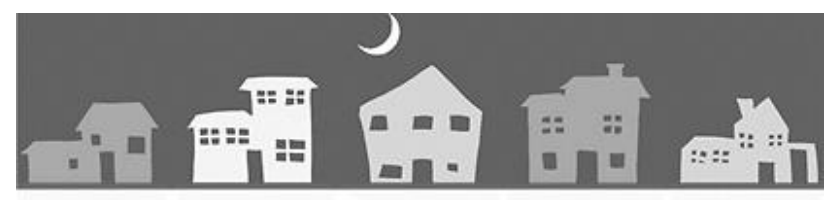

DŽENTRIFIKACIJA: SAVREMENI KOLONIJALIZAM

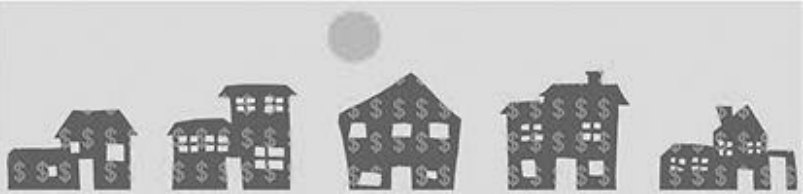

Slika 1. Ilustracija džentrifikacije Bottom of Form

Najčešće se džentrifikuju centri gradova, sa tendencijom dislokacije siromašnog stanovništva ka periferiji. U upotrebi se koristi i reč japifikacija, sa sličnim značenjem. Izraz japi (yuppie) (akronim od engleske reči young urban professional) prevodi se kao - mladi, ambiciozni, visokoobrazovani stručnjak zaposlen u gradu. Odnos društva i prostora koji se ostvaruje u okvirima savremenog grada uslovljen je specifičnom konstelacijom političkih, ekonomkih, društvenih i kulturnih faktora. Promene u ovim aspektima, izazvane procesima postsocijalističke transformacije (u zemljama Centralne i Istočne Evrope), globalizacije i jačanja neo-liberalnog kapitalizma, daju kontekst nastanku ekskluzivnih formi stanovanja džentrifikovanih naselja.

\section{DŽENTRIFIKACIJA KAO FENOMEN TRANSFORMACIJE}

Proces džentrifikacije predstavlja vidljiv fenomen preobražaja savremenih gradova i direktna je posledica sledećih širih procesa:

- restrukturiranje ekonomije na globalnom nivou - nova internacionalna podela rada i deindustrijalizacija gradova, pre svega najrazvijenijih zemalja, odnosno najrazvijenijih gradova globalnih, regionalnih i nacionalnih urbanih sistema);

- porast značaja servisne ekonomije, kulturne industrije i prostora potrošnje u oblikovanju gradova;

- nove modele upravljanja gradovima (preduzetnički grad: značaj partnerstva javnog sektora sa privatnim investitorima) i planiranja gradova (uloga brendiranja i reklamiranja grada kao robe);

- promene obrazaca socijalne stratifikacije, odnosno diverzifikacija životnih stilova i društvenih vrednosti u urbanim prostornim celinama.

Činjenica da fenomen džentrifikacije predstavlja prostornu refleksiju kompleksnih društvenih procesa i stanja uslovljava i različite pristupe njegovom razumevanju. Pojam džentrifikacije prvi put je upotrebljen još 1964. god. u sociološkoj studiji London: Aspects of Change, autorke Ruth Glass [4]. Nakon toga fenomen je teorijski i empirijski dosta proučavan, ali nije uspostavljena teorija džentrifikacije niti je postignuta saglasnost oko definicije ovog pojma. ${ }^{1}$

Džentrifikacija se pokazuje kao visoko diferenciran proces koji se dešava na različite načine u susedstvima različitih gradova, sa drugačijim putanjama promena, pa i

${ }^{1}$ www.uvidok.rcub.bg.ac.rs akterima procesa. Različite procese urbane obnove ne treba interpretirati kao faze u procesu džentrifikacije. Istraživanja su, na primer, identifikovala različite tipove obnove susedstava i džentrifikacije u zavisnosti ko su akteri procesa $\mathrm{i}$ to:

1. Japifikacija - doseljavanje mladih stručnjaka u susedstva, koje je u vezi sa nastankom nove srednje klase (zaposleni u korporativnom i finansijskom sektoru).

2. Marginalna (periferna) džentrifikacija - jer nju izvode privremeni stanovnici, koji će se preseliti u suburbiju kada budu osnovali porodicu (kategorija stanovnika centra turisti u centru).

3. Poboljšanja u susedstvu postignuta dugotrajnim akcijama samih stanovnika, koji teže da unaprede svoj stambeni prostor; u ovom slučaju ne dolazi do menjanja stanovnika, dakle, negativni socijalni efekti džentrifikacije su minimalni [5].

Gotovo je nemoguće pronaći dva istovetna procesa džentrifikacije. U zavisnosti od lokalnih uslova moguć je različiti razvoj procesa, tako se dešava u nekim slučajevima da se pojedine faze preskoče ili da se proces ne privede u potpunosti kraju. U naučnoj literaturi moguće je pronaći različite hipoteze o idealno-tipskom toku i fazama procesa džentrifikacije. Obično se izdvajaju četri faze:

- od prve faze džentrifikacije koja predstavlja dolazak novih korisnika prostora,

- laganog istiskivanja lokalnog stanovništva,

- faza dolaska ,pravih džentrifikatora“ iz više srednje klase,

- sveobuhvatne promene stanovništva, izgleda i karaktera dela grada koje će konačno, generisati profit krupnog kapitala.

Pionirska faza džentrifikacije obično počinje pojavljivanjem umetnika, studenata i pripadnika alternativne kulturne scene. Ubrzo se u kvartu otvaraju novi samoorganizovani „gerila” barovi, kulturni centri i druga mesta okupljanja, uz bujanje raznolikih pravaca umetnosti, čime se četvrt etablira kao alternativna. Ovim se praktično bez ikakvih ulaganja u modernizaciju polako menja predhodni imidž kvarta u uslovima kulturne aproprijacije. Za razliku od tradicionalo industrijskih objekata i radničkih i/ili migrantskih domova, novi lokali i druga infrastruktura alternativne kulturne scene privlače srednju klasu. Ovde se već postavlja pitanje - koliko su ovakva društvena mesta, produkovana od strane klasno nesvesnih kreativih snaga, zapravo društvena, inkluzivna i u funkciji zajednice?

U procesu transformacije alternativni kvartovi postaju sve interesantniji kako za investitore tako i za pojedince iz viših klasa. U ovoj fazi dolazi do akumulacija simboličkog kapitala i građevinske aprecijacije, što treba da prokrči put većem interesovanju za investicije i početku rasta cena komunalnih usluga i nekretnina zahvaljujući mehanizmu tržišta. Ovakve cene prinudiće prvobitne vlasnike ili korisnike da odustanu od plaćanja renti ili rasprodaju svoju imovinu jer ne mogu da priušte nova ulaganja i održavanje. U narednoj fazi simbolički kapital je realizovan kroz povećanu vrednost nekretnina. Investori se trude da cenu isplaćenu tokom kupovine što 
pre amortizuju pa tako dolazi do povećanja cena stanarine i dalje preprodaje stanova. Ovo je uobičajno praćeno renoviranjem ili čak često i ponovnom izgradnjom modernih objekata na istoj lokaciji, na taj način raste probitno investirani iznos, što se kasnije odražava i na cenu stanova i stanarina u tom delu grada. U zavisnosti od brzine, obima ali i lokalnih uslova u kojima se proces džentrifikacije odvija u nekom trenutku za veći deo prvobitnog stanovništva četvrti troškovi života postaju preveliki i oni bivaju primorani da se odsele iz dotadašnjeg komšiluka. Tokom ovog procesa ne dolazi samo do proste zamene stanovništva, već se zbog većih prosečnih primanja i drugačije strukture novih domaćinstava menjaju se potrebe za uslugama i potrošačke navike lokalne zajednice. Možda su najpoznatiji primeri berlinskih kvartova koji su se za samo deceniju ili dve transformisali od najsiromašnijih $u$ elitna, bogata $i$ prestižna mesta.

Važnost samog procesa džentrifikacije, kao i njegova globalna naučna aktuelnost, proizilazi iz činjenice da on predstavlja prostorni izraz transformacije industrijskog $\mathrm{u}$ postindustrijsko društvo $\mathrm{u}$ kontekstu ekonomskog povezivanja i nastajanja nove urbane hijerarhije [6].

\section{POSTSOCIJALISTIČKI KONTEKST DŽENTRIFIKACIJE}

Politički i ekonomski faktori koji utiču na procese urbane obnove su neodvojivi od kulturnog okvira. Kulturalističko objašnjenje ne parira, već dopunjuje objašnjenja iz aspekta političke ekonomije. Postsocijalistička transformacija je formalizovala usvajanje privatne svojine kao vrednosnog prioriteta (u odnosu na javnu - društvenu i državnu svojinu), te usvajanje slobode kao prioriteta nad bezbednošću. Kulturni okvir za ovu smenu daje nešto ranije usvajanje partikulariteta kao vrednijeg (pouzdanijeg) koncepta od univerzalnosti, a pridružuje im se i nepoverenje $u$ dugoročne ciljeve $i$ trajna rešenja $i$ normalizacija usmeravanja na kratkoročno i neposredno. Sve ovo presudno utiče na stambene politike.

Napuštanje ideje pronalaženja i zadovoljavanja univerzalnih egzistencijalnih potreba na nivou čitavog društva (uz nemogućnost kontrolisanja biološkog tela države u okolnostima globalizacije i pojačanih migracija) je delegitimizovalo socijalističku definiciju stanovanja kao potrebe, omogućivši da ono ponovo bude definisano kao roba.

Postavljanje privatne svojine kao vrednosnog prioriteta legitimizuje težnju građana da steknu i simboličkim sredstvima naglase svoj status posednika - od čega profitiraju investitori i izvođači luksuznih naselja. Povlačenje postsocijalističke države sa pozicije onoga koji pruža egzistencijalnu i fizičku bezbednost u različitoj meri opterećuje i ovlašćuje građane da se za svoju bezbednost pobrinu sami. U kontekstu napuštanja dugoročnih projekata - koji zahtevaju visoko vrednovanje trajanja i percipiraju se kao ograničavajući po slobodu napuštaju se i prakse dugoročnog prostornog i urbanističkog planiranja i briga za posledice intervencija $\mathrm{u}$ gradsko tkivo, kakve su džentrifikovana naselja.

Kao što piše Čefalvaj [7], fleksibilizacija urbanističke regulative, sprovedena u skladu sa usvojenim vrednostima slobode, privremenosti, privatne svojine i zadovoljavanja partikularnih zahteva, ponukala je investitore da pokušaju da odgovore na specifične zahteve (potencijalnih) kupaca i pronađu odgovarajuću „tržišnu nišu”. Ovi zahtevi svakako zavise i od simboličkog domena, zahvaljujući kom se vrši izgradnja identiteta i kulturna razmena. Čefalvaj naglašava da tržišni pristup objašnjava da je regulisanje bezbednosti na nivou lokalne zajednice logično u sklopu prenošenja odgovornosti na aktere na nižem nivou od gradske i državne administracije, a da politički pristup naglašava da bogate na ograđivanje pokreće strah, te da je segregacija direktan rezultat ograđivanja. Primera radi, drastičan rast broja ograđenih naselja u Pragu u periodu od 2002-2008. god. (naročito 2007-2008.) pokazuje da su investitori prepoznali zahteve kupaca za „prestižem, luksuzom i bezbednošću”. Čefalvaj tvrdi da su istraživanja pokazala da u slučaju Budimpešte ,jagma za prestižom koju ispoljavaju dobrostojeći izgleda prevazilazi i strah od kriminala i potrebu za samosegregacijom". On dalje objašnjava da većina ograđenih zajednica nije u susedstvima gde žive najbogatiji, ni u kojima ima najviše kriminala, nego u oblastima u kojima živi srednja klasa umerenih primanja. Klasno zasnovane uslove nastanka džentrifikovanih naselja zamagljuje koncept životnog stila i identitetske politike.

Projektovanje ciljeva, koje se ranije odnosilo na društveni sistem (u okviru nacionalne države) i fizičke objekte, danas se gotovo iscrpljuje u ekonomskoj sferi, u proceni projektovane dobiti na osnovu koje se legitimizuju sadašnji potezi. Ta dobit gotovo nikad nije stvarna, odnosno ostvariva ni dokaziva, ona ostaje u domenu fikcije i virtuelnosti. Osim što u uopštenom smislu ponovo ukazuje na to da u savremenoj epohi ekonomija ima prioritet nad drugim delatnostima, ovo izmeštanje je duboko povezano sa konkretnom pojavom džentrifikacije. Aktuelni projekti džentrifikacije su, naime, neretko najviše motivisani mahinacijama u finansijskoj sferi.

U Budimpešti, Pragu i Talinu džentrifikacija je dosta istraživana, i teorijski i empirijski, dok studije nekih drugih postsocijalističkih gradova, kao što su Bratislava, Ljubljana ili Varšava, nisu uopšte identifikovale džentrifikaciju kao važan proces urbanih promena [8]. Naime, u postsocijalističkim gradovima najviše su proučavani socioprostorna strukturu grada $\mathrm{i}$ njena transformacija, urbano planiranje i upravljanje u gradu i suburbanizacija. Manji broj tekstova odnosi se na transformaciju fizičke i prostorne strukture grada, promene u stambenoj politici i tržištu, i transformaciju funkcionalno prostorne strukture grada [9], dakle, na teme koje su bliske procesu džentrifikacije.

\section{ZAKLJUČAK}

O (urbanoj) džentrifikaciji koju smo definisali kao proces u kome se stare, neodržavane i zapuštene zgrade sa jeftinim stanovima ili čitavi delovi grada pretvaraju u skupo stanovanje ili rezidencijalne kvartove za dobrostojeće pripadnike srednje klase, češće se govori u negativnom kontekstu.

Iako se džentrifikacija smatra za proces koji je baziran na principima slobodnog tržišta i koji je u potpunosti motivisan neoliberalnom ekonomskom logikom, aprecijacija pojedinih gradskih četvrti može predstavljati i proces 
kojim ne upravlja isključivo tržište. Čest je slučaj kada se džentrifikacija omogućuje, ako ne i finansira javnim sredstvima i resursima, pod idejom da se poboljša imidž nekog dela grada. Ono što je apsurdno je da se poboljšanje stambenih i životnih uslova uzima kao jedan od argumenata za legitimizaciju ovih investicija, pošto obično na kraju samog procesa prvobitno stanovništvo više i nije tu da bi posvedočilo kraju procesa džentrifikacije i poboljšanju pomenutih uslova. Gotovo je nemoguće javno, transparentno i demokratski kontrolisati proces džentrifikacije. Nalik jahanju divljeg bika - možda ćete uspeti da poverujete da ga kontrolišete par sekundi, ali to je samo da bi vas lakše zbacio iz sedla i na kraju ćete se u svakako naći u blatu, bez svesti.

Da bi se proces džentrifikacije trajno sprečio potrebne su nam odlučne politike koje će voditi ka prioritizaciji socijalnog stanovanja. Samo u sistemu gde se gradi u cilju zadovoljenja potreba celokupnog društva, a ne radi ostvarivanja profita pojedinaca, proces džentrifikacije se može izbeći. Dokle god živimo u neoliberalnim gradovima čije su ekonomije bazirane na „slobodnom“ toku kapitala, svaki deo grada, bez obzira koliko bio star ili značajan, industrijski ili porodičan, lep ili neprivlačan pre ili kasnije može biti džentrifikovan u cilju ostvarivanja profita. $^{2}$

U radu su analizirani pristupi džentrifikaciji kao sociološkog i prostornog fenomena. Da li džentrifikacija ima pozitivan ili negativan kontekst uglavnom zavisi od toga u kojoj meri se prostor koristio pre džentrifikacije i koliko naglo su se navike korisnika morale promeniti. Džentrifikacija nije definisana kao nužno zlo. Sa druge strane, ukoliko ne može niža klasa koliko i viša da koritsti džentrifikovan prostor, javlja se bunt i ona se definiše kao negativan proces. Stoga, lakše je prihvatiti urbanu regeneraciju nego džentrifikaciju.

Kao tipičan fenomen postmodernog grada, proces džentrifikacije je paradoksalan jer, sa jedne strane urušava urbanitet - socio-ekonomski homogenizuje susedstva i nosi opasnost ugrožavanja društvene produkcije prostora niže dohodovnih grupa, dok se, sa druge strane, povezuje sa vizijom grada kao oslobađajućeg mesta, u kome se neguje društveno-ekonomska, kulturna, etnička i rasna različitost. Naime, u postmodernom gradu se proklamuje multikulturalizam uz istovremeni porast materijalnih i simboličkih granica u džentrifikovanim prostorima. Tako džentrifikacija potvrđuje da je postfordistički grad prestao da bude mesto susreta pripadnika različitih kultura, kao i da je izgubio glavnu karakteristiku javnog prostora podjednaku dostupnost svim građanima.

Paradoksalnost procesa se ogleda i u jazu između koncepta i prakse - u projektima džentrifikacije govori se o ,boljem gradu”, koji u praksi znači izgradnju novih objekata potrošnje po modelu koji se realizuje na više ili manje sličan način u mnogim gradovima, ali bez uvažavanja autentičnosti određenog prostora, vremena i društva [10].
Ne treba da prihvatimo, nego moramo da razumemo moćne obrasce koji oblikuju današnji grad [11].

\section{LITERATURA:}

[1] Vesselinov, E. i Cazessus, M. (2007). Gated communities and spacial inequality. Journal of urban affairs, 29(2), 109-127.

[2] Sykora, L. (2003). Economic and social restructuring and gentrification in Prague. Acta. Facultatis Rerum Naturalium Universitatis Comenianae, No. 37, 71-81.

[3] Sykora, 2003.

[4] Glass, R. (1964). London: Aspects of Change. London: MacGibbon \& Kee, 1964.

[5] Van Criekingen, M. i Decroly, J. (2003). Revisiting the Diversity of Gentrification: Neighborhood Renewal Processes in Brussels and Montreal. Urban Studies, 40(12), 2451-2468.

[6] Petrović, M. (2007). Urbana obnova, odrednica. U: Mimica A. i M. Bogdanović (ur.) Sociološki rečnik. Beograd: Zavod za udžbenike i nastavna sredstva.

[7] Cséfalvaj, Z. (2011). Gated Communities for Security or Prestige? A Public Choice Approach and the Case of Budapest. International Journal of Urban and Regional Research, 35(4), 735-752.

[8] Sykora, 2003.

[9] Kubeš, J. (2013). European post-socialist cities and their near hinterland in intraurban geography literature. Bulletin of Geography. Socio-economic Series, No. 19, 19-43.

[10] Čaldarović O. i J. Šarinić (2008). First signs of gentrification? Urban regeneration in the transitional society: the case of Croatia. Sociologija i prostor, 46(34), 181-182.

[11] Safdie, M. i Kohn, W. (1997). The city after automobile - An architect's vision. New York: Basic Books; Toronto: Stoddart Publishing Co.

\section{Kratka biografija:}

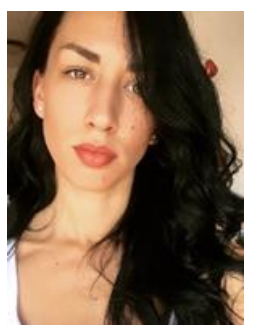

Anđela Vranić je rođena u Subotici 1991. godine. 2010. je završila gimnaziju Svetozar Marković u Novom Sadu i upisala osnovne studije na Poljoprivrednom fakultetu, smer Pejzažna arhitektura, na kojem je i diplomirala 2015. Na jesen iste godine upisuje master studije na Fakultetu tehničkih nauka, na Departmanu za arhitekturu i urbanizam, studijski program Planiranje i upravljanje regionalnim razvojem.

\footnotetext{
${ }^{2}$ www.masina.rs
} 